\title{
Spinal deformity following surgery for spinal cord tumors and tumorous lesions: analysis based on an assessment of the spinal functional curve
}

\author{
Akira Inoue, Takaaki Ikata and Shinsuke Katoh \\ Department of Orthopedic Surgery, School of Medicine, The University of Tokushima, Tokushima, Japan
}

\begin{abstract}
The mechanism of spinal deformity after surgical removal of a cervical spinal cord tumor or tumorous lesions was studied in 36 patients, based on the spinal functional curve prepared from the intersectional angle. The postoperative spinal deformity depends on the surgical level and the type of operation. In the laminectomy group, kyphosis of the upper cervical spine and compensatory increased lordosis of the lower cervical spine were observed in the C2 laminectomy patients. Localized kyphosis of the spine at the cervicothoracic junction and compensatory increased lordosis of the upper cervical vertebrae were noted in the C7 laminectomy patients. In the laminoplasty group, spinal deformities were less frequently observed, and when present the deformity was limited to a slight increase of lordosis, even in patients who had the facetectomy. These facts demonstrate the preventive effect of the laminoplasty regarding postoperative spinal deformity. Laminoplasty with reconstruction of the erector spinal muscles and the nuchal ligament is recommended for patients with a spinal cord tumor or a tumorous lesion. The spinal functional curve was significant in studying the biomechanics of the vertebral column with the advantage that both alignment and mobility of the spine are simultaneously, respectively and precisely visualized.
\end{abstract}

Keywords: spinal cord tumor; spinal neoplasms; spinal cysts; syringomyelia; cervical spine; deformity of spine following surgery

\section{Introduction}

Extensive laminectomy to approach spinal cord tumors or tumorous lesions (spinal-cord lesions hereinafter) is one of the most commonly performed surgical spinal procedures. However, there have been numerous reports on the potential disadvantages of this procedure such as the development of a progressive swan-neck deformity and of spinal instability. The causes of these unfavorable outcomes include osseoligamentous deficiencies and concomitant muscle weakness, although the actual pathophysiological mechanism is still being discussed. We introduced the spinal regional components classification method, ${ }^{1}$ and applied the surgical techniques to minimize these undesirable outcomes.

The present study involved only patients with cervical or cervicothoracic spinal-cord lesions operated on by posterior approach alone. The outcome of surgery and the postoperative deformity of the vertebral column were investigated using the method of the spinal functional curve based on the intersectional angle. 2,3

Correspondence: A Inoue

\section{Methods}

Thirty-six patients with spinal cord lesions who underwent surgery by a posterior approach alone on the cervical or cervicothoracic region in our clinic after 1974, were selected to enable us to evaluate the outcome of surgery (Table 1). There had not been any previous cervical spine surgery on these patients. At the time of operation, the patients ages ranged from 17 to 73.2 years (average: 42.5 years), and the follow up period was 0.5 to 14.2 years (average: 4.0 years). Regarding the histology of the lesions, seven patients had neuroepithelial tumors, 18 had nerve sheath tumors, two had meningeal tumors and nine had malformations or tumor-like lesions. Regarding the surgical techniques employed, laminectomy was performed in 18 patients, laminoplasty in 10 (bilateralopen; 5, hemilateral-open; 3, osteoplastic-laminotomy; 2), hemi-partial laminectomy in 7 (partial laminectomy hereinafter) and one other. The neurological status was evaluated using the scoring system for cervical myelopathy established by the Japanese Orthopaedic Association (JOA score, Table 2).

The intersectional angles at each level of the cervical spine were measured by an independent observer using a digitizer on the lateral radiographs of patients in the neutral position in maximal flexion, and in maximal extension taken before surgery and during follow up. For the postoperative evaluation, the most recent 


\begin{tabular}{|c|c|c|c|c|c|c|c|c|c|c|c|c|c|c|c|c|c|c|c|c|c|c|}
\hline \multirow[b]{2}{*}{ Case } & & \multirow{2}{*}{$\begin{array}{l}\text { Age at } \\
\text { operation } \\
\text { (years) }\end{array}$} & \multirow[b]{2}{*}{$\begin{array}{l}\text { Primary } \\
\text { Disease }\end{array}$} & \multirow{2}{*}{$\begin{array}{c}\text { Duration } \\
\text { of } \\
\text { Postop. } \\
\text { Follow-up } \\
\text { (years) }\end{array}$} & \multirow{2}{*}{$\begin{array}{l}\text { Level of } \\
\text { Tumor and } \\
\text { Tumorous } \\
\text { Lesion }\end{array}$} & \multirow{2}{*}{$\begin{array}{l}\text { Surgical } \\
\text { Level } \\
\text { of } \\
\text { Opera- } \\
\text { tion }\end{array}$} & \multirow{2}{*}{$\begin{array}{l}\text { Surgical } \\
\text { Range of } \\
\text { Operation } \\
\text { (seg- } \\
\text { ments) }\end{array}$} & \multirow[b]{2}{*}{$\begin{array}{c}\text { Surgical } \\
\text { Procedure }\end{array}$} & \multirow{2}{*}{\multicolumn{2}{|c|}{ 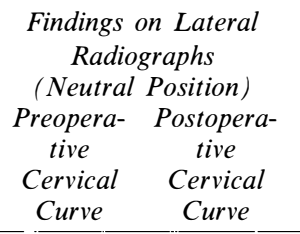 }} & \multicolumn{5}{|c|}{$\begin{array}{cc}\text { Neurological and } L \\
\text { Preoperative score } \\
\text { Motor } \quad \text { Sensory }\end{array}$} & \multirow[b]{2}{*}{$\begin{array}{c}\text { Blad- } \\
\text { der }\end{array}$} & \multicolumn{5}{|c|}{$\begin{array}{l}\text { ondition (JOA score) } \\
\text { Postoperative score }\end{array}$} & \multirow[b]{2}{*}{$\begin{array}{c}\text { Blad- } \\
\text { der }\end{array}$} \\
\hline & & & & & & & & & & & $\begin{array}{r}M o \\
U / E\end{array}$ & $\begin{array}{l}\text { tor } \\
L / E\end{array}$ & $U / E^{S}$ & $\begin{array}{c}\text { Sensory } \\
L / E\end{array}$ & $T$ & & $\begin{array}{c}M o t \\
U / E\end{array}$ & $\begin{array}{l}\text { tor } \\
L / E\end{array}$ & $U / E$ & $\begin{array}{l}\text { Sensory } \\
L / E\end{array}$ & $T$ & \\
\hline 1 & $\mathbf{M}$ & 47.3 & astrocytoma & 2.3 & $\mathrm{C} 4$ & $\mathrm{C} 2 \sim \mathrm{C} 6$ & 5 & Laminectomy & Normal & $\begin{array}{l}\text { Swan-neck } \\
\text { Deformity }\end{array}$ & 4 & 2 & 1 & 0 & 0 & 2 & 4 & 2 & 1 & 0 & 0 & 2 \\
\hline 2 & $\mathbf{M}$ & 40.8 & neurinoma & 9 & $\mathrm{C} 5 \sim \mathrm{T} 2$ & $\mathrm{C} 4 \sim \mathrm{T} 3$ & 7 & Laminectomy & Normal & $\begin{array}{l}\text { Swan-neck } \\
\text { Deformity }\end{array}$ & 4 & 3 & 1 & 1 & 1 & 2 & 4 & 3 & 2 & 1 & 1 & 3 \\
\hline 3 & $\mathbf{M}$ & 28.8 & neurinoma & 7.6 & $\mathrm{C} 2 \sim \mathrm{C} 4 / 5$ & $\mathrm{C} 2 \sim \mathrm{C} 6$ & 5 & Laminectomy & Normal & $\begin{array}{l}\text { Swan-neck } \\
\text { Deformity }\end{array}$ & 0 & 0 & 0 & 0 & 0 & 0 & 0 & 0 & 0 & 0 & 0 & 0 \\
\hline 4 & M & 21.6 & $\begin{array}{c}\text { ganglio- } \\
\text { neurinoma }\end{array}$ & 1.2 & $\mathrm{C} 1 / 2, \mathrm{C} 3 / 4$ & $\mathrm{Cl} \sim \mathrm{C} 5$ & 5 & Laminectomy & Normal & $\begin{array}{l}\text { Swan-neck } \\
\text { Deformity }\end{array}$ & 3 & 2 & 2 & 2 & 2 & 3 & 4 & 3 & 2 & 2 & 2 & 3 \\
\hline 5 & $\mathrm{~F}$ & 55.2 & neurinoma & 0.9 & $\mathrm{C} 4 \sim 6$ & $\mathrm{C} 3 \sim \mathrm{C} 6$ & 4 & Laminectomy & Normal & $\begin{array}{l}\text { Increased } \\
\text { Lordosis }\end{array}$ & 1 & 0 & 0 & 0 & 0 & 1 & 1 & 1 & 0 & 0 & 0 & 1 \\
\hline 6 & $\mathrm{~F}$ & 47.1 & neurinoma & 8 & $\mathrm{C} 5 \sim \mathrm{C} 6$ & $\mathrm{C} 5 \sim \mathrm{C} 7$ & 3 & Laminectomy & Normal & $\begin{array}{l}\text { Increased } \\
\text { Lordosis }\end{array}$ & 2 & 2 & 0 & 1 & 2 & 3 & 2 & 1 & 0 & 0 & 0 & 2 \\
\hline 7 & M & 40.2 & neurinoma & 6.5 & $\mathrm{C} 6 \sim \mathrm{C} 7$ & $\mathrm{C} 5 \sim \mathrm{T} 2$ & 5 & Laminectomy & Normal & $\begin{array}{l}\text { Increased } \\
\text { Lordosis }\end{array}$ & 4 & 3 & 2 & 0 & 0 & 2 & 4 & 3 & 1 & 0 & 0 & I \\
\hline 8 & M & 49 & neurinoma & 4.8 & $\mathrm{C} 6 \sim \mathrm{C} 7 / \mathrm{T} 1$ & $\mathrm{C} 5 \sim \mathrm{T} 2$ & 5 & Laminectomy & $\begin{array}{l}\text { Slightly } \\
\text { Lordotic }\end{array}$ & $\begin{array}{l}\text { Increased } \\
\text { Lordosis }\end{array}$ & 4 & 3 & 1 & 0 & 0 & 1 & 4 & 3 & 1 & 0 & 2 & 3 \\
\hline 9 & M & 18.2 & neurofibroma & 0.5 & $\mathrm{C} 2 \sim 3$ & $\mathrm{C} 2 \sim \mathrm{C} 3$ & 2 & Laminectomy & Normal & Straight-neck & 2 & 2 & 1 & 1 & 2 & 3 & 4 & 4 & 2 & 2 & 2 & 3 \\
\hline 10 & M & 44 & ependymoma & 14.2 & $\mathrm{C} 5 \sim \mathrm{C} 7$ & $\mathrm{C} 2 \sim \mathrm{T} 1$ & 8 & Laminectomy & $\begin{array}{l}\text { Straight- } \\
\text { neck }\end{array}$ & Straighr-neck & 1 & 3 & 0 & 0 & 0 & 2 & 1 & 1 & 0 & 0 & 0 & 1 \\
\hline 11 & M & 43.4 & ependymoma & 11.4 & $\mathrm{C} 3 \sim \mathrm{T} 1$ & $\mathrm{C} 2 \sim \mathrm{T} 1$ & 8 & Laminectomy & Normal & $\begin{array}{l}\text { Normal } \\
\text { (fused) }\end{array}$ & 3 & 3 & 0 & 1 & 1 & 2 & 2 & 1 & 0 & 0 & 0 & 1 \\
\hline 12 & M & 68.7 & neurinoma & 3.9 & C5 & $\mathrm{C} 4 \sim \mathrm{C} 6$ & 3 & Laminectomy & Normal & Normal & 1 & 2 & 0 & 0 & 0 & 3 & 3 & 4 & 1 & 2 & 2 & 3 \\
\hline 13 & M & 47.9 & meningioma & 2.3 & $\mathrm{C} 5 \sim \mathrm{C} 6$ & $\mathrm{C} 5 \sim \mathrm{C} 6$ & 2 & Laminectomy & Normal & Normal & 4 & 3 & 2 & 1 & 1 & 2 & 4 & 4 & 2 & 2 & 1 & 3 \\
\hline 14 & M & 36.2 & neurinoma & 3.9 & $\mathrm{C} 4 / 5$ & C4 $\sim \mathrm{C} 5$ & 2 & Laminectomy & Normal & Normal & 3 & 2 & 1 & 0 & 1 & 2 & 3 & 3 & 1 & 2 & 2 & 3 \\
\hline 15 & M & 43 & neurinoma & 1.6 & $\mathrm{C} 7 / \mathrm{T} 1 \sim \mathrm{T} 2$ & $\mathrm{C} 7 \sim \mathrm{T} 2$ & 3 & Laminectomy & Normal & Normal & 4 & 1 & 2 & 0 & 0 & 1 & 4 & 3 & 2 & 1 & 1 & 2 \\
\hline 16 & $\mathrm{~F}$ & 37.6 & lipoma & 6.1 & $\mathrm{C} 6 / 7 \sim \mathrm{C} 7 \mathrm{~T} 1$ & $\mathrm{C} 7 \sim \mathrm{T} 2$ & 3 & Laminectomy & Normal & Normal & 3 & 1 & 0 & 1 & 1 & 1 & 3 & 1 & 0 & 1 & 1 & 1 \\
\hline 17 & M & 21.1 & neurinoma & 0.9 & $\mathrm{Cl}$ & $\mathrm{C} 1 \sim \mathrm{C} 2$ & 2 & Laminectomy & Normal & Normal & 1 & 2 & 1 & 2 & 2 & 3 & 4 & 3 & 1 & 2 & 2 & 3 \\
\hline 18 & $\mathrm{~F}$ & 62.9 & neurinoma & 9.9 & $\mathrm{C} 1 / 2 \sim \mathrm{C} 2 / 3$ & $\mathrm{Cl} \sim \mathrm{C} 2$ & 2 & Laminectomy & Normal & Normal & 1 & 2 & 0 & 1 & 1 & 3 & 4 & 4 & 2 & 2 & 2 & 3 \\
\hline 19 & $\mathrm{~F}$ & 37.1 & ependymoma & 8.4 & $\mathrm{C} 4 \sim 7$ & $\mathrm{C} 1 \sim \mathrm{T} 2$ & 9 & open & Normal & Straight-neck & 2 & 3 & 0 & 0 & 0 & 2 & 3 & 2 & 0 & 0 & 0 & 2 \\
\hline 20 & M & 47.8 & neurinoma & 1.3 & $\mathrm{C} 4 / 5 \sim \mathrm{C} 6 / 7$ & $\mathrm{C} 5 \sim \mathrm{C} 6$ & 2 & $\begin{array}{l}\text { Hemilateral- } \\
\text { open }\end{array}$ & Normal & $\begin{array}{l}\text { Increased } \\
\text { Lordosis }\end{array}$ & 4 & 3 & 1 & 0 & 1 & 3 & 4 & 4 & 1 & 1 & 2 & 3 \\
\hline 21 & $\mathrm{~F}$ & 47 & syringomyelia & 4.8 & $\mathrm{C} 3 \sim \mathrm{T} 4$ & $\mathrm{C} 7 \sim \mathrm{T} 2$ & 3 & $\begin{array}{l}\text { Osteoplastic- } \\
\text { laminotomy }\end{array}$ & Normal & Normal & 3 & 4 & 1 & 2 & 2 & 3 & 3 & 0 & 0 & 0 & 2 & 2 \\
\hline 22 & $\mathrm{~F}$ & 34.6 & neurinoma & 5 & C5 & C5 $\sim 6$ & 2 & $\begin{array}{l}\text { Osteoplastic- } \\
\text { laminotomy }\end{array}$ & Normal & Normal & 2 & 2 & 0 & 2 & 0 & 4 & 4 & 4 & 1 & 2 & 2 & 3 \\
\hline 23 & $\mathrm{~F}$ & 40.4 & $\begin{array}{l}\text { cavitation of } \\
\text { spinal cord }\end{array}$ & 0.5 & C5 & $\mathrm{C} 4 \sim \mathrm{C} 5$ & 2 & $\begin{array}{l}\text { Bilateral- } \\
\text { open }\end{array}$ & Normal & Normal & 1 & 2 & 0 & 0 & 0 & 4 & 1 & 2 & 0 & 0 & 0 & 3 \\
\hline 24 & $\mathbf{M}$ & 66.3 & neurinoma & 2.7 & $\mathrm{C} 6 / 7 \sim \mathrm{T} 1$ & $\mathrm{C} 7 \sim \mathrm{T} 1$ & 2 & $\begin{array}{l}\text { Bilateral- } \\
\text { open }\end{array}$ & Normal & Normal & 4 & 0 & 2 & 0 & 1 & 1 & 4 & 1 & 2 & 2 & 1 & 2 \\
\hline 25 & M & 47.3 & astrocytoma & 0.9 & $\mathrm{C} 6 \sim \mathrm{T} 1$ & $\mathrm{C} 5 \sim \mathrm{T} 1$ & 4 & $\begin{array}{l}\text { Bilateral- } \\
\text { open }\end{array}$ & Normal & Normal & 3 & 3 & 1 & 1 & 2 & 3 & 4 & 4 & 1 & 1 & 2 & 3 \\
\hline 26 & $\mathrm{~F}$ & 48.8 & neurinoma & 3.4 & $\mathrm{C} 7 \sim \mathrm{T} 1$ & $\mathrm{C} 7 \sim \mathrm{T} 2$ & 3 & $\begin{array}{l}\text { Hemilateral- } \\
\text { open }\end{array}$ & Normal & Normal & 4 & 0 & 2 & 0 & 0 & 1 & 4 & 3 & 2 & 1 & 1 & 2 \\
\hline 27 & $\mathrm{~F}$ & 28.6 & $\begin{array}{l}\text { enterogenous } \\
\text { cyst }\end{array}$ & 2.9 & $\mathrm{C} 6 / 7 \sim \mathrm{T} 1 / 2$ & $\mathrm{C} 7 \sim \mathrm{T} 1$ & 2 & $\begin{array}{l}\text { Hemilateral- } \\
\text { open }\end{array}$ & Normal & Normal & 4 & 4 & 2 & 2 & 2 & 3 & 4 & 4 & 1 & 2 & 2 & 3 \\
\hline 28 & $\mathrm{~F}$ & 24.9 & syringomyelia & 2 & $\mathrm{C} 3 \sim 5$ & $\mathrm{C} 3 \sim \mathrm{C} 6$ & 4 & $\begin{array}{l}\text { Bilateral- } \\
\text { open }\end{array}$ & $\begin{array}{l}\text { Straight- } \\
\text { neck }\end{array}$ & Normal & 4 & 4 & 0 & 2 & 2 & 3 & 4 & 4 & 0 & 0 & 0 & 3 \\
\hline
\end{tabular}



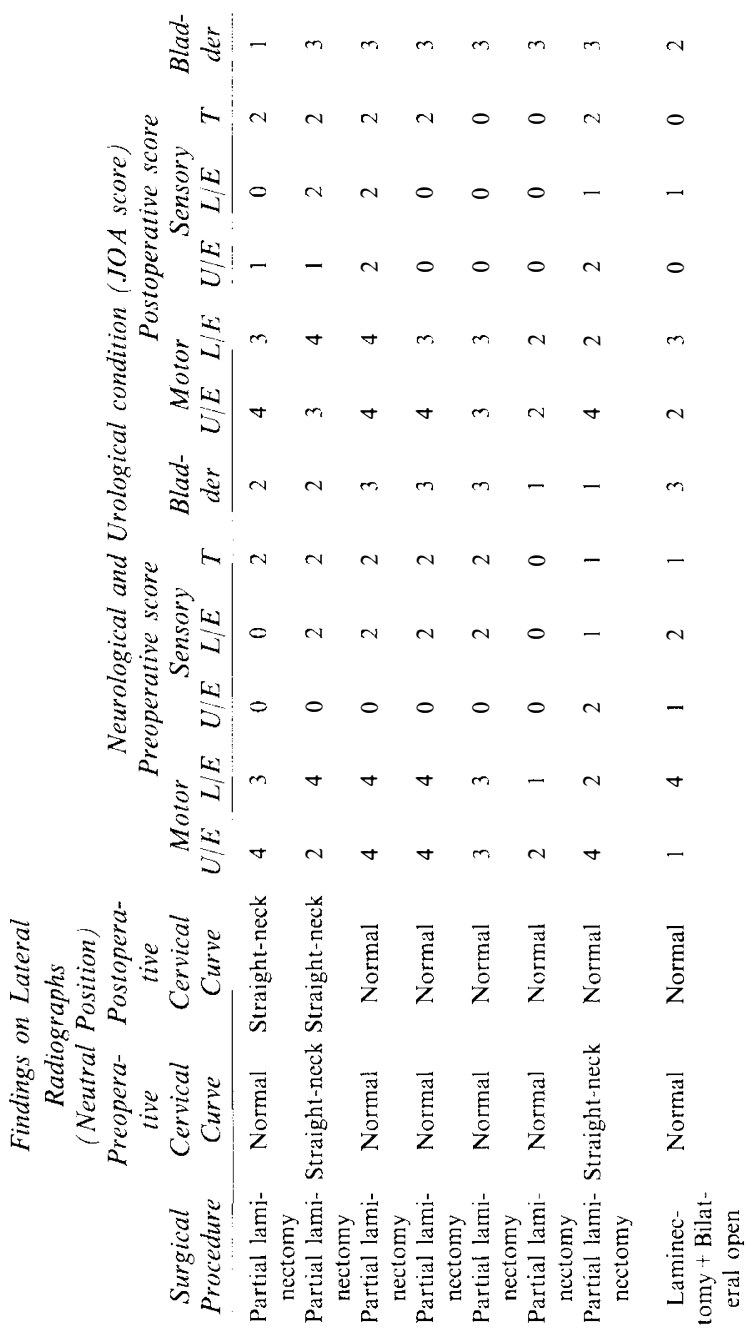

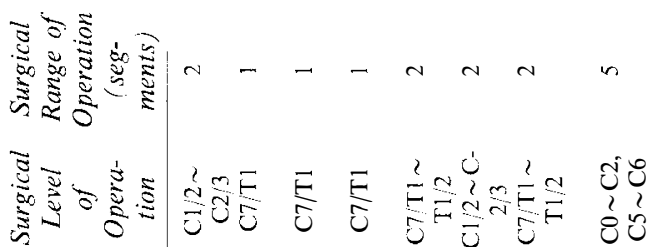

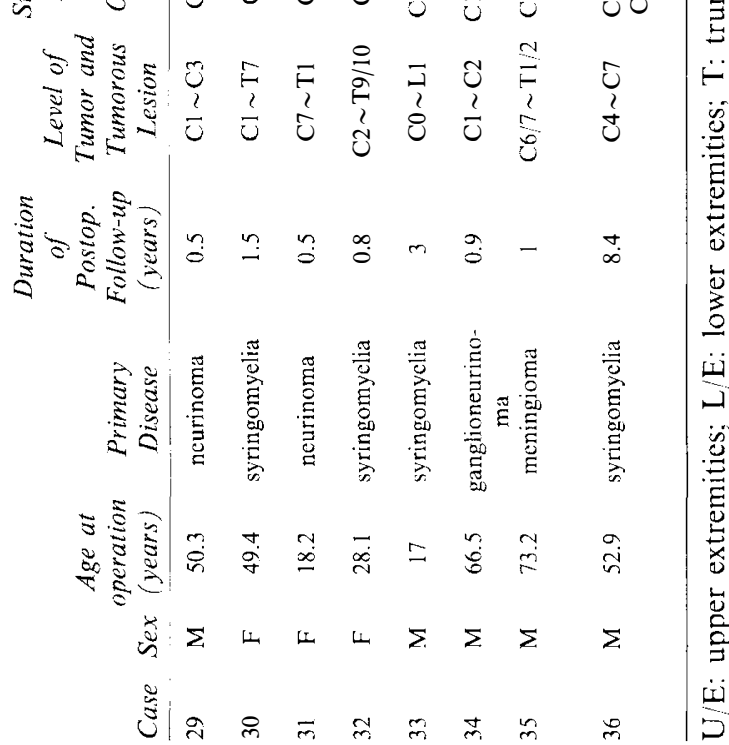

radiographs were used. According to the method of White, ${ }^{2}$ a tangential line was drawn at the caudal aspect of each vertebral body, and the adjacent intersectional angle was determined. When the adjacent tangential lines crossed anteriorly to the vertebral body, the angle was considered as 'plus' or positive, and when they crossed posteriorly, it was considered as 'minus' or negative (Figure 1). The 'plus' or positive value of the intersectional angle indicate a kyphotic vertebral column alignment, and the 'minus' or negative value indicates a lordotic vertebral column alignment. Each intersectional angle was plotted, and the spinal functional curve was made from the line segments which connected the spinal neutral position, in maximal flexion, and in maximal extension, respectively. The difference between the functional curve at maximal flexion and maximal extension indicates each intersectional range of motion. The difference between maximal flexion and the neutral position indicates the flexion range of motion, while that between the neutral position and maximal extension indicates the extension range of motion.

Thirty volunteers ranging from 15 to 78 years of age (average: 44.7 years) who demonstrated no neurologi-

Table 2 Scoring system for cervical myelopathy established by the Japanese Orthopaedic Association in 1975

I. Motor function

A. Upper extremeties

0 . Impossible to eat with either chopsticks or spoon

1. Possible to eat with spoon, but not with chopsticks

2. Possible to eat with chopsticks, but inadequate

3. Possible to eat with chopsticks, but clumsily

4. Normal

B. Lower extremeties

0 . Impossible to walk

1. Need cane or aid on flat ground

2. Need cane or aid only on stairs

3. Walks independently, but clumsily

4. Normal

II. Sensory function

A. Upper extremeties

0 . Apparent sensory loss

1. Minimal sensory loss

2. Normal

B. Lower extremeties same as $\mathrm{A}$

C. Trunk

same as A

III. Bladder function

0 . Urinary retention and/or incontinence

1. Severe disturbance inadequate evacuation of the bladder, straining, dripping of urine

2. Mild disturbance urinary retardation, pollakiuria

3. Normal 


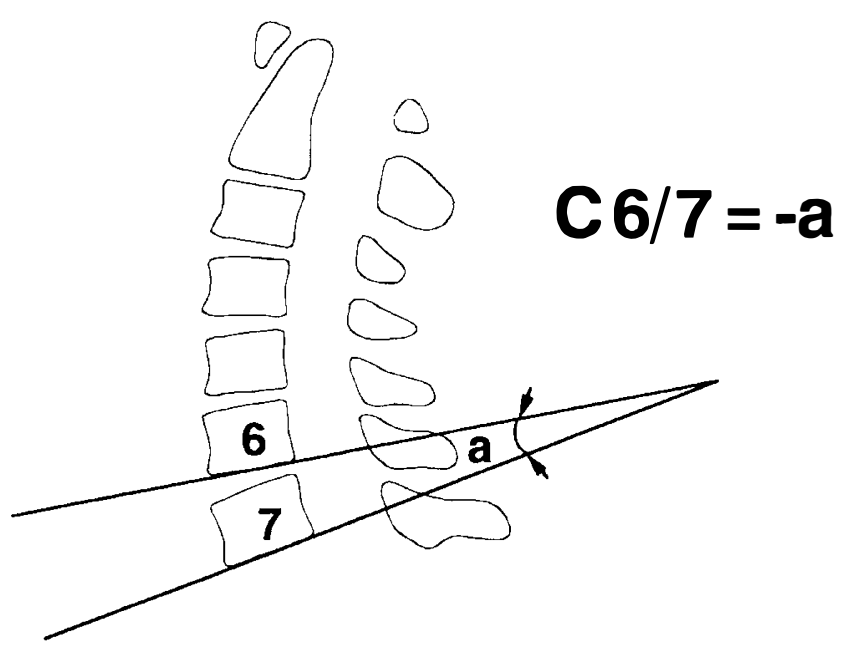

Figure 1 Measurement of the intersectional angle

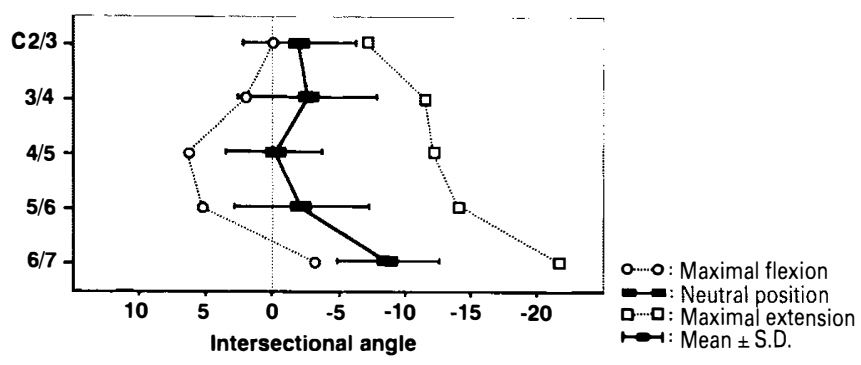

Figure 2 Spinal functional curve in the control group

cal symptoms such as pain or restricted range of motion were selected for the control group, and the functional curve was applied for this group. In the control group, the line segment that connected $\mathrm{C} 2 / 3$ and $\mathrm{C} 3 / 4$ was almost vertical, and slightly convex from $\mathrm{C} 4 / 5$ to $\mathrm{C} 6 / 7$. The intersectional angle at $\mathrm{C} 4 / 5$ was almost zero, and each intersectional angle was negative, reflecting the lordotic cervical alignment (Figure 2). The ratio of the flexion range of motion to the extension range of motion in the control group was about 1 to 2 .

\section{Results}

Patients were divided into three groups: the laminectomy group $(n=18)$; the laminoplasty group $(n=10)$; and the partial laminectomy group $(n=7)$. In the laminectomy group, $61 \%(n=11)$ of the patients had postoperative spinal deformities, including a swan-neck deformity in $22 \%(n=4)$, increased lordosis in $22 \%$ $(n=4)$, and a straight-neck in $11 \%(n=2)$ and fused spine in $6 \%(n=1)$, which were significantly high compared with $20 \%(n=2)$ of the patients in the laminoplasty group, and $22 \%(n=2)$ in the partial laminectomy group presented with spinal deformities.
In the laminectomy group, postoperative deformities was compared with respect to age, sex and the number of laminae removed. The average age at operation of patients with postoperative deformities $(n=11)$ was $39.6 \pm 11.8$ years, and that of patients with a normal curve $(n=7)$ was $45.3 \pm 16.3$ years. The average number of laminae removed was $5.2 \pm 1.9$ for patients with postoperative deformities $(n=11)$; and $2.4 \pm 0.5$ for those with a normal curve $(n=7)$. There was a statistically significant difference as for the number of laminae removed (unpaired $t$ test, $P<0.01$ ), but no correlation was found for the age and sex of the patients. Regarding the neurological and urological states of the patients prior to and subsequent to operation (Table 3), the incidence of postoperative deformity was statistically low in patients with a good postoperative neurological recovery (unpaired $t$ test, $P<0.05)$.

Concerning the level of laminae removed, the postoperative deformities were mainly swan-neck deformity in $\mathrm{C} 2$ resected cases, and increased lordosis in $\mathrm{C} 7$ resected cases. Patients in whom both $\mathrm{C} 2$ and C7 laminae were preserved showed an almost normal curve pattern. Of the two patients who had both $\mathrm{C} 2$ and C7 laminae resected, one had a straight-neck, and the other had almost normal alignment with spontaneous posterior fusion.

The relationship between mobility of the spine and the change of alignment was studied based on the spinal functional curve. The partial laminectomy group demonstrated a neutral alignment of the functional curve similar to that shown in the control group, while the laminectomy group showed an increased lordotic curve, and the laminoplasty group showed a decreased lordotic curve. The intersectional range of motion was well preserved both in flexion and in extension in the partial laminectomy group, but the flexion range of motion was limited in the laminectomy group, and the extension range of motion was limited in the laminoplasty group (Figure 3).

The relation between the surgical level and cervical alignment was examined in the laminectomy group, which demonstrated a high incidence of deformities

Table 3 Neurological and urological states prior to and subsequent to laminectomy (JOA score)

\begin{tabular}{|c|c|c|c|}
\hline & & $\begin{array}{c}\text { With } \\
\text { deformity } \\
(\mathrm{n}=11)\end{array}$ & $\begin{array}{c}\text { Without } \\
\text { deformity } \\
(\mathrm{n}=7)\end{array}$ \\
\hline $\begin{array}{l}\text { Motor and } \\
\text { sensory } \\
\quad(\text { normal }=14)\end{array}$ & $\begin{array}{c}\text { Prior to operation } \\
\text { Subsequent to } \\
\text { operation }\end{array}$ & $\begin{array}{l}6.8 \pm 3.5 \\
6.6 \pm 4.9\end{array}$ & $\begin{array}{r}6.7 \pm 2.5^{\mathrm{NS}} \\
11.3 \pm 2.6^{*}\end{array}$ \\
\hline $\begin{array}{l}\text { Bladder } \\
\quad(\text { normal }=3)\end{array}$ & $\begin{array}{c}\text { Prior to operation } \\
\text { Subsequent to } \\
\text { operation }\end{array}$ & $\begin{array}{l}1.9 \pm 0.9 \\
1.8 \pm 1.1\end{array}$ & $\begin{array}{l}2.1 \pm 0.9^{\mathrm{NS}} \\
2.6 \pm 0.8^{\mathrm{NS}}\end{array}$ \\
\hline
\end{tabular}

Mean \pm SD; NS: not significant using unpaired $t$ test; $* P<0.05$ 
(Figure 4). Although slightly restricted extension was observed, patients in whom $\mathrm{C} 2$ and $\mathrm{C} 7$ laminae were preserved demonstrated a curve close to that of the control group. On the other hand, those whose C2 lamina was removed presented a very sharp curve convexing from the left with its maximum curvature at $\mathrm{C} 4 / 5$, reflecting the remarkable kyphotic upper-middle spine alignment accompanied with increased lordosis in the lower cervical spine, resulted in a swan-neck deformity. A restricted range of motion in the direction of flexion was also observed in these

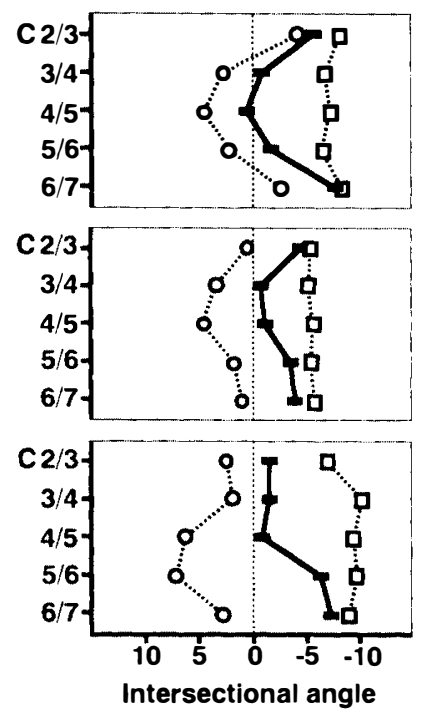

\section{Laminectomy $(n=18)$}

Laminoplasty

$(n=10)$

\section{Partial \\ laminectomy $(n=7)$}

O.... : Maximal flexion ㅁ..ㅁ: Maximal extension

Figure 3 Postoperative spinal functional curve in each group

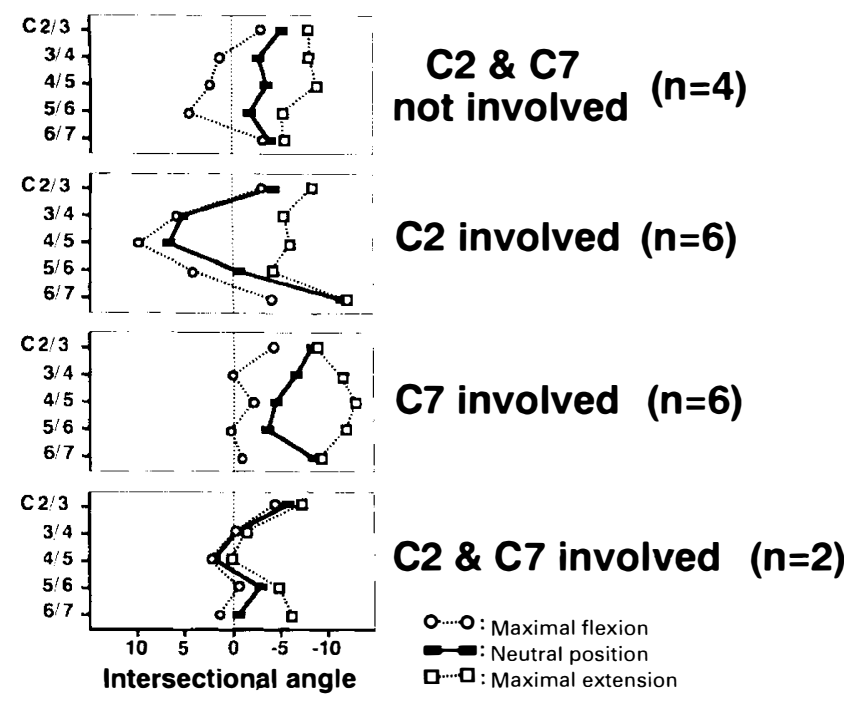

Figure 4 Postoperative spinal functional curve in the laminectomy group by the surgical level

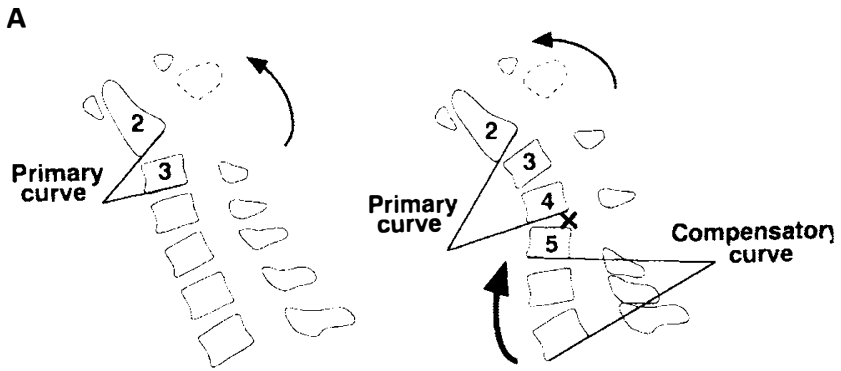

B
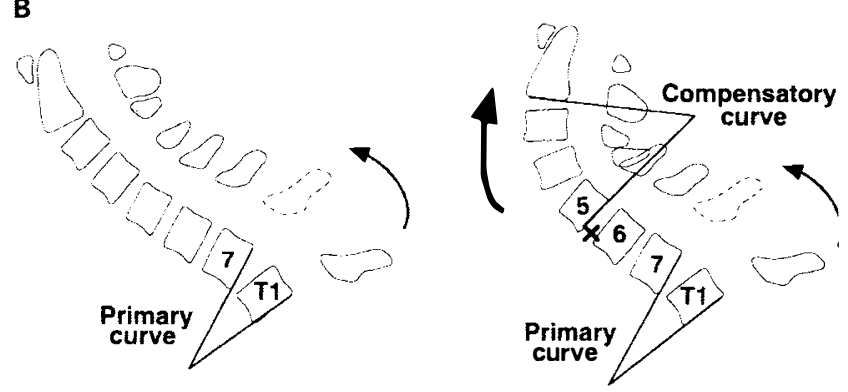

Figure 5 Mechanism of development of spinal deformities. (A) When the C2 lamina is removed. (B) When the C7 lamina is removed

patients. In particular, a neutral alignment at $\mathrm{C} 2 / 3$ and $\mathrm{C} 3 / 4$ was obtained at maximal flexion, and that at C6/7 was at maximal extension. When the C7 lamina was resected, the curve was convex from the right with its maximal curvature at $\mathrm{C} 5 / 6$, which reflected the increased lordosis of the upper cervical spine. In particular, a neutral alignment at $\mathrm{C} 6 / 7$ which was at maximal extension was caused by a severe local kyphosis at $\mathrm{C} 7 / \mathrm{T} 1$. Patients who had both $\mathrm{C} 2$ and C7 laminae removed showed an intermediate curve pattern between that of the $\mathrm{C} 2$ lamina removed patients and that of the $\mathrm{C} 7$ lamina removed patients in neutral alignment, but almost lost the intersectional range of motion in flexion and extension, probably reflecting the spontaneous posterior fusion.

\section{Discussion}

The operative approach for a spinal tumor with minimal damage of spinal-vertebral structures are one of the main concerns of surgeons when treating patients with spinal-cord lesions. ${ }^{\top}$ However, a conventional extensive laminectomy has been widely performed to approach spinal-cord lesions in spite of the fact that the procedure can be associated with extensive damage to the spine. There are many reports regarding severe cervical spine deformity following extensive laminectomies. ${ }^{4-10}$ The deformity is usually accompanied by a compensatory lordosis and is known as the 'swan-neck' deformity. ${ }^{6,11}$ Other studies report the development of a kyphotic deformity of the cervical spine following multiple bilateral laminectomies. ${ }^{5}$ But the mechanism for these cervical spine deformities is still being discussed. ${ }^{5,6,7,9,12,13}$ 
Various methods have been reported to assess instability and alignment of the cervical spine..$^{2,9,14,15}$ However, many of them have focused on changes of a single intervertebral segment, or on the alignment of the cervical vertebrae as a whole. Munechika, ${ }^{16}$ discussed the functional curve, which is composed of each vertebral segment mobility at maximal flexion and extension as a means of assessment. In the present study, we considered a spinal functional curve, ${ }^{3}$ based on the intersectional angle to assess postoperative spinal deformities. With this method, both local and total changes can be evaluated in detail, and spinal mobility and spinal alignment can be visualized at the same time. There have been several reports on identifiable risk factors for the development of a spinal deformity following an extensive laminectomy, including the age at operation, ${ }^{4,5,6,8,9,12,17}$ the number of laminae resected, ${ }^{9}$ the extent of destruction of facets joints, ${ }^{8,14,18-22}$ the curve pattern of spine before operation, ${ }^{9,23}$ the surgical level, ${ }^{4,7,9}$ the neurological state ${ }^{4}$ the history of radiation therapy, ${ }^{4}$ the period of post-operative external support ${ }^{4}$ and others. In our series, the number of laminae resected, the surgical level, the operation modus and the postoperative neurological state actually affected the development of post operative deformities.

According to our results, a kyphotic deformity of the upper cervical spine and compensatory lordosis of the lower cervical spine developed in the C2 lamina removed patients (Figure 5A). In the $\mathrm{C} 7$ lamina removed patients, a local sharp kyphosis developed at the level of the cervicothoracic junction accompanied by a secondary compensatory lordosis of the upper cervical spine (Figure 5B). These data imply that the pattern of deformity depends on the laminectomy level, as Sim et $a l^{6}$ and Fraser et $a l^{7}$ mentioned, and the prevalence of the deformity depends on the postoperative neurological states. On the other hand, the incidence of an abnormal spinal curve pattern was observed less frequently in the laminoplasty group and in the partial laminoplasty group than in the laminectomy group. These findings confirm that preserving the function of the posterior osseoligamentous complex ${ }^{21,24,25}$ and the paravertebral muscles $5,9,26,27$ is important to maintain cervical stability after surgery.

Considering our results, in all patients who require an extensive laminectomy of $\mathrm{C} 2$ and/or C7 laminae, laminoplasty should also be adopted. In this way, reconstruction of the ligamentous connection and reattachment of the paravertebral erector muscles, including the semispinalis cervicis and semispinalis capitis muscles to the spinous processes, are made, thereby diminishing spinal deformity after surgery. ${ }^{26}$ Careful attention should be paid to patients with upper cervical cord tumors, especially dumbbell tumors, as there are risk factors for substantial deformity and instability, such as bulbous enlargement of the posterior arch and intervertebral foramen, vertebral scalloping and the necessity of sacrificing the facet joints in combination with laminectomy. When there is a high risk factor for the development of a spinal deformity, even if laminoplasty was performed, an additional operation to obtain stabilization is indicated.

Early evaluation of the possible risk for deformity and instability following operation permits suitable prompt intervention including bracing. ${ }^{8}$ The preventive effect of bracing and its efficacy, however, is still under discussion. ${ }^{6}$ Herman and Sonntag, ${ }^{28}$ considered that immediate fixation with anterior plating facilitates solid fusion, maintains the spinal curvature, and promotes neurological improvement. Callahan et a ${ }^{29}$ and Farcy et $a l^{30}$ preferred posterior fusion in such patients. Crawford, ${ }^{31}$ mentioned that anterior disc excision and bone graft followed by posterior arthrodesis with instrumentation are indicated when the kyphotic angle is greater than 50 degrees, or if scoliosis is greater than 80 degrees.

In this series, the patients in whom both $\mathrm{C} 2$ and $\mathrm{C} 7$ laminae removed had a fairly normal spinal alignment in the neutral position, but mobility of the spine was severely impaired; that is termed a 'fused spine'. The normal mobility of the spine is also an important factor. Goel et $a l^{32}$ reported an increase in spinal motion of about $10 \%$ after laminectomy, but Mikawa et $a l^{13}$ and Wetzel et $a l^{33}$ reported that the mobility of the spine decreased after operation. Ishida et $a l^{34}$ mentioned that laminectomy caused a decrease of spinal movement, especially during extension; probably as a result of functional insufficiency of the paraspinal muscles.

Although partial laminectomy is only indicated for a small spinal cord tumor (one vertebral segment), we consider that this technique is preferable compared with laminectomy and laminoplasty, because the spinal and paraspinal structures can be almost completely preserved. In our series, both the alignment and the mobility of the spine were well preserved after operation. Especially, in case of patients with tumors derived from nerve sheath cells and were located on one side of the spinal canal, then most of the tumor could be easily resected by partial laminectomy. Even dumbbell tumors could be resected by a partial laminectomy and facetectomy operation.

In conclusion, we consider that the spinal functional curve based on the intersectional angle is significant for the assessment of the biomechanics and deformity of the spine. Laminoplasty with reconstruction of the erector muscles and nuchal ligament is mandatory for patients with spinal-cord lesions, to maintain both stability and mobility of the spine to the maximum after operation. Moreover, partial laminectomy is the best procedure for the maintenance of both the alignment and the mobility of the spine in selected patients.

\section{References}

1 Inoue A, Ikata T, Murase M, Katoh S. Surgical planning for cervicospinal tumorous lesions on the basis of 'new' spinal regional components (RC) classification method. The Proceeding of the 21st Cervical Spine Research Society 1993; 21: 105-107. 
2 White III AA, Johnson RM, Panjabi MM, Southwick WO. Biomechanical analysis of clinical stability in the cervical spine. Clinical Orthop 1975; 109: 85-96.

3 Inoue A et al. Clinical analysis of cervical spine deformity following two operations for spinal cord tumor. J Japan Paraplegia 1994; 7: 292-293.

4 Tachdjian MO, Matson DD. Orthopaedic aspects of intraspinal tumors in infants and children. J Bone J Surg 1965; 47A: 223 248.

5 Cattel HS, Clark GL. Cervical kyphosis and instability following multiple laminectomies in children. J Bone J Surg 1967; 49A: $713-720$.

6 Sim FH et al. Swan-neck deformity following extensive cervical laminectomy. J Bone J Surg 1974; 56A: 564-580.

7 Fraser RD, Paterson DC, Simpson DA. Orthopaedic aspect of spinal tumors in children. J Bone J Surg 1977; 59B: 143 - 151.

8 Lonstein JE. Post-laminectomy kyphosis. Clin Orthop 1977; 128: $93-100$.

9 Katsumi Y, Honma T, Nakamura T. Analysis of cervical instability resulting from laminectomies for removal of spinal cord tumor. Spine 1989; 14: 1171-1176.

10 Butler JC, Whitecloud TS 3d. Postlaminectomy kyphosis. Causes and surgical management. Orthop Clin North Am 1992; 23: $505-$ 511.

11 Horowitz T. Structural deformities of the spine following bilateral laminectomy. AJR 1941; 46: 836.

12 Yasuoka S, Peterson HA, MacCarty CS. Incidence of spinal column deformity after multilevel laminectomy in children and adults. J Neurosurg 1982; 57: $441-445$.

13 Mikawa Y, Shikata J, Yamamura T. Spinal deformity and instability after multilevel cervical laminectomy. Spine 1987; 12: $6-11$.

14 White III AA, Panjabi MM. Clinical Biomechanics of the Spine, 2nd edn. JB Lippincott: Philadelphia, 1990.

15 Lee $\mathrm{S}$ et al. In vivo kinematics of the cervical spine. Part I: Development of a roentgen stereophotogrammetric technique using metallic markers and assessment of its accuracy. $J$ Spinal Disord 1993; 6: $522-534$.

16 Munechika Y. Influence of laminectomy to stability of spine. An experimental study with special reference to the extent of laminectomy and the resection of intervertebral joint. $J$ Jap Orthop Ass 1973; 47: 101 - 126. (In Japanese).

17 Wilberger JE, Maroon JC. Occult posttraumatic cervical ligamentous instability. J Spinal Disord 1990; 3: 156-161.
18 Raimondi AJ et al. Laminectomy and total reconstruction of the posterior spine arch for spinal canal surgery in childhood. $J$ Neurosurg 1976; 45: 555-560.

19 Raynor RB, Pugh J, Shapiro I. Cervical facetectomy and its effect on spine strength. J Neurosurg 1985; 63: $278-282$.

20 Cusik JF et al. Biomechanics of cervical spine facetectomy and fixation techniques. Spine 1988; 13: 808-812.

21 Whitehill $\mathrm{R}$ et al. Cervical ligamentous instability in a canine in vivo model. Spine 1987; 12: 959-963.

22 Zdeblick TA et al. Cervical stability after foraminotomy. A biomechanical in vitro analysis. J Bone J Surg 1992; 74A: 22 - 27.

23 Mayfield JK, Erkkila JC, Winter RB. Spine deformity subsequent to acquired childhood spinal cord injury. J Bone J Surg 1981; 63A: $1401-1411$.

24 Panjabi MM, White III AA, Johnson RM. Cervical spine mechanics as a function of transection of components. $J$ Biomechanics 1975; 8: $327-336$.

25 Fielding JW. The nuchal ligament. Spine 1976; 1: 3-14.

26 Nolan JR, Sherk HH. Biomechanical evaluation of the extensor musculature of the cervical spine. Spine 1988; 13: 9-11.

27 Southern EP, Pelker RR, Crisco JJ, Panjabi MM. Posterior element strength six months postinjury in the canine cervical spine. J Spinal Disord 1993; 62: 155-161.

28 Herman JM, Sonntag VK. Cervical corpectomy and plate fixation for postlaminectomy kyphosis. J Neurosurg 1994; 80: $963-970$.

29 Callahan RA et al. Cervical facet fusion for control of instability following laminectomy. J Bone J Surg 1977; 59A: 991-1002.

30 Farcy JP, Weidenbaum M, Sola C. Surgical management of severe cervical kyphosis following extensive laminectomies. Spine 1990; 15: $41-45$.

31 Crawford AH. Pitfalls of spinal deformities associated with neurofibromatosis in children. Clin Orthop 1989; 245: 29-42.

32 Goel VK, Clark CR, Harris KG, Schulte KR. Kinematics of the cervical spine: effects of multiple total laminectomy and facet wiring. J Orthop Res 1988; 6: 611-619.

33 Wetzel FT, Panjabi MM, Pelker RR. Temporal biomechanics of posterior cervical spine injuries in vivo in a rabbit model. $J$ Orthop Res 1989; 7: 728-731.

34 Ishida et al. Critical analysis of extensive cervical laminectomy. Neurosurgery 1989; 24: 215-222. 